\title{
Preferência pela liquidez: o novo contexto financeiro internacional inviabiliza a teoria?
}

\author{
Liquidity preference: the new international financial \\ arrangements invalidate the theory?
}

\begin{abstract}
ADRIANA MOREIRA AMADO*, ${ }^{1}$
RESUMO: O artigo analisa uma questão muito frequente no debate acadêmico entre diferentes escolas de pensamento: a relevância da teoria da preferência pela liquidez sob os novos arranjos financeiros internacionais e nacionais. A questão principal aqui é assinalar que esses novos arranjos deram demasiada liquidez aos ativos financeiros não monetários que tornaram irrelevante o atributo liquidez do dinheiro; portanto, a preferência pela liquidez perde seu significado. O artigo demonstra que, sob as suposições de Keynes, que sustentam a teoria da preferência pela liquidez, esse novo arranjo enfatiza e fortalece vários motivos para exigir dinheiro e não o contrário, reforçando assim a validade da teoria.

PALAVRAS-CHAVE: Globalização; preferência pela liquidez; Keynes.
\end{abstract}

ABSTRACT: The paper analyses a question that is very frequent in the academic debate among different schools of thought: the relevance of the liquidity preference theory under the new international and national financial arrangements. The main issue here is to point out that those new arrangements gave too much liquidity to non-monetary financial assets that made irrelevant the liquidity attribute of money; therefore, liquidity preference loses its meaning. The paper demonstrates that under Keynes assumptions, which support liquidity preference theory, this new arrangement emphasizes and strengthens several motives for demanding money and not the contrary, reinforcing in this way the validity of the theory. KEYWORDS: Globalization; liquidity preference; Keynes.

JEL Classification: B50; E12; E41.

\footnotetext{
* Professora do Departamento de Economia da Universidade de Brasília, Brasília/DF, Brasil, e-mail: uctpama@unb.br. Submetido: outubro 2002; aceito: dezembro 2003.

${ }^{1} \mathrm{~A}$ autora agradece o financiamento do $\mathrm{CNPq}$ à pesquisa.
} 


\section{INTRODUÇÃO}

Uma das características da década de 1990 é o acelerado processo de inovação financeira que ocorreu, não apenas em nível nacional, mas também em nível internacional. Essas inovações culminaram com o aparecimento de novos ativos financeiros que têm uma liquidez extremamente elevada e com o ganho de liquidez pela maioria dos ativos financeiros já existentes em decorrência da ampliação dos mercados em que os mesmos são transacionados Carvalho (1997), Plihon (1995) e Kregel (1996).

Surge neste ponto uma nova característica do referido período que diz respeito à ampliação das fronteiras dos mercados nacionais. Essa ampliação, em grande parte, foi conseqüência do processo de globalização que promoveu a unificação de parte dos mercados financeiros nacionais. As próprias moedas nacionais passaram a ser transacionadas nesse mercado, os ganhos com a especulação com a taxa de câmbio passando a ter um peso significativo nos ganhos globais dos grandes investidores Carvalho (1997), Plihon (1995) e Kregel (1996), Mollo e Amado (2000) e Brunhoff (1982).

Esse processo foi acelerado e facilitado pela própria atuação dos Estados nacionais ao abrirem as contas de capitais de seus respectivos países, facilitando a movimentação do capital entre os mesmos e permitindo que esse movimento desse margem a ganhos com a especulação, não só associada aos diversos ativos nacionais, que agora tornam-se acessíveis aos diversos agentes, bem como o "preço", ou as variações dos mesmos, das moedas nacionais, cuja oscilação gera um potencial de ganho relevante para os especuladores. Concomitantemente a esse processo, observase a dessegmentação interna dos diversos mercados financeiros nacionais, criando também uma maior volatilidade em cada um desses mercados (Plihon, 1995; Chesnais, 1995; e Brunhoff, 1982).

Nesse novo contexto, tem surgido um questionamento relativamente freqüente, por parte de alguns acadêmicos, ${ }^{2}$ sobre se ainda faz sentido a teoria da preferência pela liquidez de Keynes, uma vez que já se possui ativos que têm uma liquidez extremamente elevada e há o acesso fácil a moedas internacionais que podem ter uma credibilidade maior do que as diversas moedas domésticas, a combinação desses dois elementos poderia perfeitamente fazer com que outros ativos desempenhassem o papel que caberia às moedas nacionais na teoria keynesiana. ${ }^{3}$

Logicamente, este questionamento não vem de autores próximos, teoricamente, a Keynes, mas de qualquer forma, mostra que há problemas associados à compreen-

\footnotetext{
2 Normalmente, esses questionamentos ocorrem informalmente em seminários, discussões, etc., demonstrando um grande desconhecimento da área acadêmica de questões associadas à teoria da preferência pela liquidez. Nesse sentido, cremos que o artigo contribua para esclarecer e sistematizar parte desses questionamentos.

${ }^{3}$ Esta é uma das discussões levantadas por Dow (1997).
} 
são da teoria que devem ser esclarecidos e o caminho para chegar-se à resposta a esta questão deve ser demonstrado para que não haja nenhum tipo de dúvida em relação ao papel da moeda em economias monetárias de produção, e que o papel da moeda em questão apenas é plenamente desempenhado pela moeda nacional.

O trabalho objetiva exatamente mostrar que o papel da moeda na teoria keynesiana é ampliado dentro deste novo contexto e que ela continua atuando como referência de liquidez nas economias monetárias de produção. Nesse sentido, em uma primeira seção será definida liquidez e demonstrado que não há uma dicotomia absoluta entre ativos líquidos e ativos ilíquidos, mas sim uma escala de liquidez e que na década de 1990 o que ocorreu foi uma aproximação dos diversos ativos, no que tange ao atributo de liquidez, do ativo referência: a moeda. Em uma segunda seção, iremos mostrar porque a moeda é demandada por si mesma em economias monetárias de produção e quais são os elementos que geram essa demanda. Em uma terceira seção mostraremos por que apenas a moeda nacional dá uma resposta adequada aos motivos que geram a demanda por moeda. Finalmente, nessa seção, iremos mostrar que o ganho de liquidez por parte de diversos ativos e a ampliação dos mercados em que os mesmos são transacionados ampliaram a volatilidade e a instabilidade das diversas economias nacionais e ao fazerem isso acentuaram a preferência pela liquidez dos diversos agentes. DesSa forma, ao invés desSe novo contexto reduzir o poder analítico da teoria da preferência pela liquidez, ele o ampliou em escala considerável.

\section{MOEDA E LIQUIDEZ}

A liquidez de um ativo é definida como a propriedade de transformação do referido ativo em outra mercadoria qualquer instantaneamente. A medida de liquidez tem, portanto, dois componentes: o primeiro refere-se à velocidade de transformação, e o segundo à capacidade de manter valor quando esta velocidade é infinita. Normalmente, observa-se um trade-off entre essas duas dimensões do processo, o que reduz a liquidez dos ativos. Há, contudo, um terceiro aspecto relativo à liquidez que se refere à "probability of one of realising its full value immediately” (Chick, 1983, p. 304).

Assim, a liquidez mede a flexibilidade que um ativo ou mercadoria dá ao seu detentor. A moeda é, normalmente, considerada o ativo líquido por excelência, e isso é uma conseqüência de ela ser imediatamente conversível no meio de pagamento e, conseqüentemente, em todas as mercadorias, ou seja, o custo de transação ${ }^{4}$ envolvido na moeda é nulo. Contudo, quando o atributo relativo à probabilidade

\footnotetext{
${ }^{4}$ Cabe ressaltar que o custo de transação dos demais ativos representa, em grande medida, o fato de eles não embutirem um nível adequado de informações, o que faz com que os mesmos dêem uma resposta inadequada à incerteza (Goodhart, 1989).
} 
de transformação do valor da moeda é considerado, a liquidez da mesma pode ser reduzida.

As análises desenvolvidas por Keynes estavam muito associadas às economias fechadas. Isso decorrendo, em parte, do contexto histórico em que estava inserido o autor. Contudo, o que pretendemos mostrar aqui é que as conclusões geradas por sua teoria são válidas também em um contexto de rápida abertura dessas economias. Não apenas as conclusões são preservadas, mas o que se observa é que os problemas associados à questão da preferência pela liquidez são enfatizados e ampliados, uma vez que em nível global o desenvolvimento e aprofundamento dos mercados financeiros leva ao acirramento do comportamento especulativo dos agentes (Keynes, 1936). Dessa maneira, a divisão feita por Keynes entre especuladores e investidores, na Teoria Geral (1936), em um contexto de aprofundamento do mercado financeiro tende a privilegiar os especuladores fazendo que eles tenham a dominância no processo econômico e ampliando dessa forma os problemas associados à instabilidade que os mesmos geram, conforme observado em Plihon, 1995, e Chick, 1983.

Como Keynes assume as elasticidades de produção e substituição da moeda negligíveis e observa os salários nominais como rígidos, ${ }^{5}$ ele acaba assumindo que o termo associado à probabilidade de conversão da liquidez da moeda é um. Ou seja, em decorrência de todos os atributos que descrevem a liquidez, a moeda é o limite máximo no que se poderia considerar uma "escala da liquidez" (Chick, 1983).

Analisados esses elementos relativos à liquidez da moeda, podemos observar os elementos que interferem na liquidez de outros ativos ou mercadorias de forma a diferenciar a liquidez dos mesmos em diferentes níveis. Essa diferenciação pode ser observada em Keynes, 1936.

Dessa forma, pode-se perceber facilmente que a liquidez dos ativos relacionase de forma direta com arranjos institucionais, especialmente com a organização dos mercados à vista, o que permite a redução de custos de transação e com a dimensão dos mesmos (Davidson, 1980, p. 298). Dessa maneira, o rápido processo de abertura das contas de capitais observadas, sobretudo, a partir da década de 1990, contribuiu de forma substantiva para aproximar a liquidez de grande parte dos ativos financeiros de vários países e para aproximar esse conjunto do referencial de liquidez que é determinado pela moeda nacional, uma vez que ampliou e agilizou os mercados em que os mesmos são transacionados. Gerou, também, a inclusão das próprias moedas nacionais no conjunto de ativos financeiros com os quais passou a se especular, dado que o movimento da taxa de câmbio passa a ser também uma importante fonte de ganho ou perda de capital (Brunhoff, 1982). Todavia, essa ampliação da esfera especulativa decorrente do aprofundamento e desenvolvimento dos mercados financeiros, é suposta por Keynes e verificada como

\footnotetext{
${ }^{5}$ Neste ponto, há uma circularidade, como será discutido posteriormente.
} 
base para o motivo especulação ainda em uma análise para economias fechadas (Keynes, 1936, cap. 12). O que se observa em uma economia aberta é exatamente a intensificação do motivo especulação. Todavia, o referencial de liquidez, mesmo com a aproximação dos diversos ativos nacionais e internacionais, em que podem ser incluídas as próprias moedas nacionais, continua sendo a moeda nacional e, portanto, a teoria da Preferência pela Liquidez está plenamente preservada.

Como veremos, a capacidade de um ativo desempenhar o papel de reserva de valor em uma economia monetária de produção vai depender, em grande medida, da liquidez que se atribui ao mesmo. Uma vez que a função de reserva de valor é conseqüência do valor atribuído à flexibilidade em economias monetárias, assim, quanto mais líquido o ativo, maior a flexibilidade a que está sujeito o seu possuidor.

Resta saber, portanto, por que a moeda é o elemento que tem o atributo máximo da liquidez. Ou visto de outra forma, por que é ela que ocupa a posição de limite superior na escala de liquidez e continua a desempenhá-lo, mesmo em economias globalizadas.

O caráter monetário da acumulação decorre da liquidez que a moeda apresenta nessas economias. A liquidez está associada à flexibilidade que esse ativo possui, uma vez que a flexibilidade é a resposta a duas características essenciais das economias monetárias de produção: ${ }^{6}$ a presença de tempo histórico e, conseqüentemente, da incerteza. A liquidez da moeda deve-se em grande parte ao fato de o trabalho ser o insumo mais comum, geral, das economias monetárias de produção, e de sua remuneração ser feita em termos monetários, e essa remuneração ter por base contratos que são, também, monetários, o que, em certo sentido, fornece uma âncora à moeda (Keynes, 1979, vol. XXIX e 1936). ${ }^{7}$

As particularidades da moeda em economias monetárias de produção é que dão ao salário nominal uma certa rigidez, e não a rigidez do salário nominal que gera a possibilidade de desemprego invonluntário. Essa interpretação tanto é correta que a suposição da rigidez dos salários nominais é relaxada no capítulo XIX da Teoria Geral, e os resultados que são encontrados por Keynes vão no sentido do reforço da possibilidade e profundidade da crise em economias monetárias de produção.

Uma vez que os salários e a maioria dos demais contratos são determinados em moeda nacional, esta é a que atrai para si o atributo de liquidez máxima. O que ocorre com o desenvolvimento financeiro associado à globalização e à conseqüente abertura das contas de capitais é uma aproximação dos vários ativos, com seus ganhos de liquidez, do referencial de liquidez que é representado pela moeda nacional e a conseqüente ampliação da esfera da especulação no sistema como um todo. Contudo, em momento algum a moeda perde seu papel de referência de liquidez.

\footnotetext{
${ }^{6}$ As características fundamentais das economias monetárias de produção são muito bem discutidas em Carvalho, 1992.

${ }^{7}$ Para uma análise detalhada dessa discussão, ver Davidson, 1978.
} 
É exatamente da relação apontada acima que sai a noção da insubstituibilidade da moeda na teoria da preferência pela liquidez, já que apenas ela pode ser o limite superior da liquidez e o que lhe dá esse atributo é sua relação com os salários nominais. Portanto, por mais que diversos ativos financeiros ganhem liquidez e que moedas internacionais sejam transacionadas em diversos mercados, apenas a moeda doméstica é o referencial de liquidez, pois só ela dá base para os contratos salariais e só ela embute o nível máximo de informações, conforme observado por Goodhart (1989).

A ampliação do uso das diversas moedas nacionais como mais um instrumento de especulação é um dos elementos que favorece a instabilidade no sistema financeiro internacional e amplia a vulnerabilidade das economias domésticas. Este é um dos pilares da crítica que se faz ao sistema de taxas de câmbio flexíveis observada a partir da quebra do sistema de Bretton Woods (Carvalho, 2000; Dow, 1993; Davidson, 1982; Guttman, 1994). Os próprios movimentos especulativos associados à valorização e desvalorização do câmbio é um dos elementos associados aos bruscos movimentos cambiais da década de 1990, não só em economias periféricas (México, Rússia, Sudeste Asiático, Brasil), bem como nas próprias economias centrais (saída da Inglaterra do Sistema Monetário Europeu em decorrência da desvalorização da libra).

Fica claro, portanto, que o fato de economias monetárias de produção possuírem contratos de trabalho monetários faz uma grande diferença em termos da determinação das trajetórias de crescimento. Por esse motivo, Keynes denomina essas economias, de forma alternativa, de economias de salário monetário (money-wage economy). Contudo, a compreensão da relevância da moeda nas mesmas não fica completa apenas com a análise da relação trabalho, produção, contratos monetários de trabalho. Falta um elemento fundamental para compreender a importância que a moeda assume nas mesmas: a observação das especificidades da moeda. É dessas especificidades que sai a possibilidade de crises em economias monetárias de produção.

Dessa maneira, fica claro que o tipo de abordagem desenvolvida por Keynes para economias fechadas, apenas se aprofunda e amplia quando tratamos de economias inseridas na nova dinâmica financeira internacional, caracterizada pela livre movimentação financeira.

\section{ECONOMIAS MONETÁRIAS DE PRODUÇÃO E PREFERÊNCIA PELA LIQUIDEZ}

As economias monetárias de produção caracterizam-se por estarem sujeitas ao tempo histórico, à incerteza e terem a moeda como uma de suas categorias fundamentais. Podemos observar em Keynes que as economias monetárias de produção são aquelas em que: 
Money plays a part of its own and affects motives and decisions and is, in short, one of the operative factors in the situation, so that the course of events cannot be predicted, either in the long period or in the short, without a knowledge of the behaviour of money between the first state and the last. (Keynes, 1973a, pp. 408-9)

A caracterização geral dessas economias, ou seja, a presença de tempo histórico e incerteza faz com que as mesmas gerem um determinado comportamento dos agentes em relação à moeda, e esse comportamento manifesta-se em sua demanda por moeda. Keynes observa fundamentalmente quatro motivos para demandar moeda.

Na Teoria Geral ele define esses motivos como: ${ }^{8}$ motivo transação, motivo precaução e motivo especulação. Nos debates de 1937, que sucederam a publicação da Teoria Geral, Keynes acrescenta o motivo finança aos motivos já citados. ${ }^{9}$

Esses motivos podem ser descritos como:

i) The transaction-motive, i.e. the need of cash for the current transaction of personal and business exchanges; ii) the precautionary-motive, i.e. the desire for security as to the future cash equivalent of a certain proportion of total resources; and iii) the speculative motive, i.e. the object of securing profit from knowing better than the market what the future will bring forth. (Keynes, 1936, p. 170)

O primeiro motivo, o motivo transação, tem uma influência marcante da demanda por moeda como definida pela teoria convencional. Ou seja, ela aparece basicamente como uma função da renda corrente da economia, e mais, é considerada uma função estável dessa variável. Seus determinantes estão associados a arranjos institucionais, como os períodos de pagamentos e recebimentos. A incerteza não tem um papel definido nesse motivo ${ }^{10}$ para demandar moeda, apesar de em um certo sentido estar presente nele. Dow (1999) relativiza essa posição em:

Within a domestic economy, the national currency is generally the asset which is most liquid and most stable in value. But within the in-

\footnotetext{
${ }^{8}$ Cabe observar que nesta obra ele está trabalhando com uma economia fechada, contudo, passar a pensar em uma economia aberta não altera substantivamente esses motivos, mas sim altera a sua composição e inter-relação, como será observado adiante.

${ }^{9}$ Davidson, 1978, p. 161, observa que ao caracterizar os depósitos de renda e de negócios como tendo como uma de suas determinações a antecipação de despesas pessoais e de negócios, Keynes estava antecipando o motivo finança nesse trabalho, contudo, a relevância desse motivo desaparece na Teoria Geral, só sendo recuperado nos seus trabalhos posteriores (Keynes, 1973, b, c, d).

${ }^{10}$ Apesar de que se formos pensar na função meio de pagamento, teremos que incluir a análise da incerteza, pois em última instância é ela que justifica essa função (Goodhart, 1989).
} 
ternational economy, there are a range of moneys. As long as each has a stable value in relation to the others, then the most liquid of these is generally employed as a means of payment and unit of account; this would normally be the national currency of the economy concerned. But, where the domestic value of the national currency is falling significantly relative to foreign currencies, because inflation or a depreciating exchange rate, other currencies may better satisfy liquidity preference. This is more likely to be the case the more free is capital mobility, i.e. the more liquid is foreign currency. It is a matter of relativities. (Dow, 1999, p. 154)

Esta citação mostra a aproximação das várias moedas do padrão de liquidez que é a moeda nacional, contudo, não elimina a importância da mesma, isto ocorrendo, apenas, em casos de dinâmicas monetárias excessivamente deterioradas.

O segundo motivo, o motivo precaução, refere-se ao caráter incerto das economias monetárias de produção. Enquanto o motivo transação supõe uma certa previsão dos recebimentos e das despesas, de forma que os saldos monetários são reduzidos a zero no fim de cada período, o motivo precaução refere-se exatamente ao caráter incerto de determinadas despesas ou a possibilidades de ganhos de mercado absolutamente imprevistas pelo agente. Contudo, apesar de basear-se na incerteza, esse motivo mantém uma relação estável com o nível de renda. E, nesse sentido, na determinação da demanda por moeda, ele aparece junto com o motivo transação como sendo uma função estável do nível de renda.

Dow (1995) observa que, em economias com graus diversos de incerteza, a preferência pela liquidez associada a este motivo varia apontando problemas relativos ao investimento em economias que apresentem um nível maior de preferência pela liquidez.

O terceiro motivo apresentado por Keynes na Teoria Geral, enfatiza o papel fundamental, enquanto reserva de valor, que a moeda desempenha nas economias monetárias de produção. Esse motivo refere-se basicamente ao caráter de apostas, cassino, das economias monetárias de produção que decorre do tipo de incerteza que caracteriza essas economias. Quando os agentes especulam estão interessados nos ganhos de capital que a retenção de um ou outro ativo pode lhes proporcionar. Nesse sentido, a mudança de um ativo a outro, em decorrência de possíveis ganhos de capital decorrentes de mudanças nas expectativas dos agentes, só é possível se não houver perda substancial de valor do ativo em questão. O caráter líquido dos ativos que desempenham o papel de reserva de valor é uma conseqüência do desenvolvimento institucional do sistema.

Este motivo está associado à ampliação da participação dos agentes que têm um caráter especulativo e têm suas ações relacionadas a essa perspectiva. Plihon (1996) observa a divisão dos agentes em duas perspectivas básicas: aqueles que formam suas expectativas e determinam suas ações com base em rendimentos de longo prazo e no comportamento dos fundamentos da economia e, por outro lado, 
aqueles que agem com base em um comportamento mimético convencional e que estão preocupados com os movimentos de curto prazo dos preços dos ativos, que refletem muito mais a "psicologia do mercado" do que fatores reais. O autor mostra que uma das características do processo de globalização é a expressiva ampliação desse segundo tipo de agente, isto ocorrendo, em grande medida, pelo favorecimento que o novo contexto financeiro internacional dá às possibilidades de especulação. Há, assim, um círculo vicioso em que as características do novo sistema financeiro internacional favorecem o fortalecimento do comportamento especulativo e o reverso também ocorre. Dessa maneira, a economia internacional e as economias nacionais são lançadas em um ambiente muito mais instável e ficam em posição muito mais vulneráveis.

Nesse sentido, há um trade-off entre o motivo precaução e o motivo especulação no que concerne à evolução do mercado financeiro e à conseqüente liquidez que os ativos comercializados nesses mercados apresentam. ${ }^{11}$ Em ambientes em que os mercados são menos desenvolvidos, os agentes tendem a manter uma proporção maior de suas poupanças em moeda, como forma de garantir liquidez para pagar despesas imprevistas ou fazer face a ganhos imprevistos de capital, mas, como esses mercados são menos ativos, o comportamento jogador, apostador, dos agentes é menos desenvolvido, e a moeda não é demandada de forma a gerar ganhos futuros de capital. Ao contrário, se os mercados financeiros forem muito desenvolvidos, os ativos transacionados nesses mercados apresentam elevada liquidez, o que permite aos agentes manterem o seu poder de compra de forma quase líquida sem a necessidade de demandar moeda. Por outro lado, como esses mercados são muito desenvolvidos, a volatilidade das expectativas e a possibilidade de ganhos de capital decorrentes de captar futuros movimentos no mercado, faz com que os indivíduos demandem moeda de forma a realizar esses ganhos esperados de capital. (Keynes, 1936, p. 170).

Quando temos mercados financeiros bem desenvolvidos, o que os indivíduos procuram não é o ganho decorrente da taxa de juros durante a vida útil do ativo de capital em questão, mas eles buscam antecipar mudanças no mercado que levem a mudanças nos preços dos ativos financeiros, de forma a obter ganhos de capital com esse movimento, vendendo esses ativos em seus preços mais elevados e comprando-os em seus preços mais baixos. Daí a relação com a taxa de juros, quanto maior a taxa de juros, mais agentes acreditarão que ela irá cair e mais facilmente abrirão mão da liquidez.

Contudo, a percepção desses dois pontos é uma questão subjetiva. A determinação de um valor seguro para esses elementos é um elemento convencional, e essa é a razão para que os indivíduos apresentem esse comportamento jogador, acreditando que suas apostas são mais corretas que as do mercado como um todo. Se os

\footnotetext{
${ }^{11}$ Aqui fica claro que o próprio ganho de liquidez pelos ativos financeiros fortalece a diferenciação da moeda em relação aos demais ativos.
} 
agentes não confiarem no estado das expectativas, eles vão postergar suas decisões de compra de ativos financeiros e tenderão a manter moeda e esperar por uma conjuntura mais favorável em que as expectativas sejam mais favoráveis (Keynes, 1937).

Dessa forma, apenas a divisão da sociedade em altistas e baixistas pode dar estabilidade ao preço dos ativos financeiros, e a taxa de juros é exatamente o elemento que equilibra esses dois grupos.

Keynes observa que a preferência pela liquidez varia negativamente com a taxa de juros: taxas de juros baixas podem levar os agentes a acreditarem que ela está muito próxima ao nível convencionalmente e subjetivamente estabelecido como seguro e, assim, podem transformar parte dos altistas em baixistas, aumentando, dessa maneira, a demanda por moeda pelo motivo especulação. Ao mesmo tempo, taxas de juros baixas reduzem o custo de oportunidade decorrente da perda dos juros por manter moeda e não ativos que rendem juros (Keynes, 1936, p. 202). Há também um terceiro efeito a ser considerado: baixas taxas de juros tendem a elevar o nível de renda, via ampliação do investimento, isso levando a um crescimento da demanda por moeda decorrente dos motivos transação e precaução.

Assim, podemos observar que a preferência pela liquidez está fundamentalmente ligada à incerteza, uma vez que os dois motivos que a determinam estão inerentemente relacionados ao caráter incerto das economias monetárias. Ao mesmo tempo, podemos observar que o desenvolvimento do sistema financeiro é um elemento fundamental para que esse motivo ganhe importância na economia. Quando observamos os questionamentos acerca do uso de novos ativos financeiros como elementos capazes de eliminar a preferência pela liquidez, isso nos parece absolutamente improcedente, pois a existência desses ativos tende a exacerbar o caráter especulativo da demanda por moeda, e a garantia contra a incerteza, associada ao desenvolvimento desses ativos, só pode ser provida pela moeda e no caso específico pela moeda nacional que por um lado tem o atributo máximo de liquidez, pelos motivos previamente anunciados e/ou é o elemento ao qual está associado o maior número de informações, o que a faz ser o meio de pagamento nacional (Goodhart, 1989).

Dessa maneira, podemos perceber que o processo de globalização financeira não gera nenhuma razão específica que possa inviabilizar a teoria da preferência pela liquidez, nem lhe reduz a importância, uma vez que, ao analisar os diversos motivos que geram a demanda por moeda, percebemos que eles podem não ser alterados ou mesmo serão ampliados com a abertura das contas de capitais e a mobilidade entre ativos.

Podemos perceber que o motivo transacional continua profundamente associado às moedas locais. O motivo precaucional, pode, em parte, ser atendido por moedas estrangeiras (em casos de dinâmicas monetárias pouco saudáveis), mas, mesmo nesses casos, guarda relação com as moedas nacionais e tende a ser ampliado com o acirramento da instabilidade econômico-financeira que tem caracterizado o processo de globalização, dado que ele é fundamentalmente decorrente da in- 
certeza e o motivo especulação tem diversas razões para se ver ampliado, uma vez que o próprio processo de globalização leva a uma profunda ampliação dos mercados financeiros, da gama de ativos que estão disponíveis e à velocidade de movimentação entre esses ativos, acirrando, assim, o caráter especulativo da economia e ampliando a participação dos agentes que se caracterizam por motivações curto-prazistas e pelo uso de processos de formação de expectativas associados a convenções e comportamentos miméticos. Esse fato tende a ampliar a instabilidade do sistema econômico e, ao fazer isso, ampliar a incerteza e conseqüentemente, a própria preferência pela liquidez.

Esses são basicamente os motivos ou incentivos para reter liquidez conforme observado na Teoria Geral. Em trabalhos posteriores, Keynes (1973 b e c) observa um quarto motivo para que a preferência pela liquidez seja ampliada. Esse é o chamado motivo finança. Esse motivo diz respeito à liquidez necessária entre o momento que o agente planeja um determinado gasto e o momento em que ele efetivamente o realiza. O caráter desse gasto não está, contudo, claro. Normalmente, o investimento é considerado a principal fonte para o motivo finança, dado o seu caráter ocasional e a dimensão do mesmo. Essas duas características podem ocasionar a necessidade do empresário de fazer algumas reservas em cash, antes que a despesa efetivamente ocorra. ${ }^{12}$

Com relação a este último motivo, também não há razões claras que levem a uma redução da provisão de liquidez para atendê-lo dentro de uma perspectiva de uma economia globalizada.

A relação entre o motivo finança e o investimento é observada por diversos autores e sua relação com outras despesas planejadas é muitas vezes desconsiderada.

Uma vez analisados os motivos que levam os agentes a demandar moeda, é necessário observar os elementos que limitam essa demanda ou que redirecionam essa demanda para outros ativos. A taxa de juros é exatamente o elemento que dá incentivos para os agentes abrirem mão do paraíso perfeito que os ativos plenamente líquidos representam e entrar num mundo incerto das mercadorias ou dos ativos que rendem juros.

O novo contexto financeiro internacional, marcado pela abertura financeira e liberalização cambial das economias, aprofundou o lado ou a importância dos agentes que têm seus objetivos associados às variações de preços de curto prazo dos ativos e, que, portanto, tomam suas decisões com base muito mais em convenções do que em qualquer outro elemento que tenha um "lastro real” (Plihon, 1995). Assim, a taxa de juros em Keynes é um fenômeno monetário e depende da prefe-

\footnotetext{
${ }^{12}$ Contudo, conforme mencionado anteriormente, essa posição não é consensual na literatura. Davidson (1978, cap. 7) reestrutura a demanda por moeda enquanto meio de troca, baseando-se nas despesas planejadas e não na renda corrente, como prevêem os motivos transação e precaução (Keynes, 1973c, p. 220). Kregel (1984-5) chama a atenção para o caráter especial do investimento que o separa das demais despesas planejadas e particulariza o motivo finança.
} 
rência pela liquidez dos agentes e das condições da oferta de moeda, uma vez que o motivo especulação desempenha um papel fundamental na determinação da demanda por moeda ${ }^{13} 13$ e é uma função do valor esperado da taxa de juros (Shackle, 1983).

Nesse sentido, a demanda por moeda nacional continua sendo um fenômeno fundamental para explicar o comportamento da taxa de juros. Contudo, agora, as expectativas de ganhos de capital são muito mais voláteis dada a ampliação do leque de ativos financeiros com os quais os agentes lidam. Isso gera uma maior volatilidade no processo de formação de expectativas dado que as convenções são mais fluidas em decorrência da maior dimensão e profundidade desses mercados.

Dessa maneira, tende a haver uma ampliação da instabilidade nesse contexto, e essa ampliação tem impactos diretos na incerteza a que estão sujeitos os agentes e, assim, há um aprofundamento da preferência pela liquidez.

Como a moeda continua apresentando suas duas características fundamentais — baixas ou negligíveis elasticidades de produção e substituição —, ela continua sendo o elemento que coloca limites ao processo de acumulação real da economia, já que a teoria da preferência pela liquidez se mantém.

Dessa forma, a instabilidade da demanda por moeda se traduz em instabilidade da taxa de juros, o que acentua a primeira e tem conseqüências fortes sobre o investimento, ao mesmo tempo em que em economias globalizadas essa instabilidade acaba tendo repercussões sobre a taxa de câmbio, o que acentua ainda mais a incerteza e tem repercussões sobre a demanda por moeda.

Fica claro, então, que os elementos que geram a demanda por moeda, em suas várias condições, estão associados à liquidez máxima possuída por esse ativo e às especificidades das economias monetárias de produção, particularmente, à noção de tempo e incerteza que permeiam essas economias.

Como visto anteriormente, um dos fatores fundamentais que confere liquidez à moeda é o fato de ela dar base aos contratos salariais e, como esses contratos são denominados em moeda nacional, apenas a moeda doméstica possui o prêmio máximo de liquidez, já que apenas ela se converte instantaneamente em todos os outros ativos com perfeita manutenção de seu valor no processo de conversão. Nesse sentido, o desenvolvimento financeiro e a maior liquidez que ele dá aos diversos ativos financeiros é incapaz de eliminar o papel da moeda nacional enquanto referência de liquidez. Ao mesmo tempo, a ampliação do uso de diversas moedas nacionais no mercado financeiro internacional, não faz com que nenhuma delas elimine o papel nacional que cada padrão monetário tem a desempenhar, dado que o contrato salarial e os demais contratos continuam tendo por base as moedas domésticas, e isso lhes confere liquidez.

\footnotetext{
${ }^{13}$ Shackle observa "Keynes's theory of employment has at its heart the rate of interest, and the rate of interest in its turn has its central nerve in the speculative motive for holding money". (Shackle, 1983, p. 209).
} 


\section{GLOBALIZAÇÃO, FINANCEIRIZAÇÃO \\ E PREFERÊNCIA PELA LIQUIDEZ}

Como visto na seção 2, há um trade-off entre o motivo precaução e a especulação. ${ }^{14}$ Quanto mais desenvolvidos os mercados financeiros, menor a demanda precaucional e maior seu componente especulativo. Por outro lado, o maior desenvolvimento do sistema financeiro também se relaciona com a liquidez dos ativos transacionados nos mesmos, conforme observado anteriormente, dado que a liquidez guarda relação com a organização, dimensão e profundidade dos mesmos. Assim, o processo recente de inovações financeiras domésticas e internacionais, por um lado, deu aos ativos financeiros uma liquidez inédita ${ }^{15}$ (Carvalho, 1997) ao mesmo tempo em que esse mesmo desenvolvimento financeiro, ou financeirização da economia, ampliou a esfera de atuação da especulação, dando uma lógica própria à acumulação financeira que, em certo sentido, a afastou da dinâmica de acumulação real (Plihon, 1995). E ao ampliar a esfera da especulação, ampliou a demanda por liquidez pelo motivo especulação.

Esse descolamento financeiro da esfera real e o ganho de importância da especulação na atividade econômica geral, com as próprias moedas sendo transacionadas como ativos financeiros, faz com que o que Keynes observava para uma economia fechada se expanda para a economia internacional. ${ }^{16}$

If I may be allowed to appropriate the term speculation for the activity of forecasting the psychology of the market, and the term enterprise for the activity of forecasting the prospective yield of assets over their whole life, it is by no means always the case that speculation predominates over enterprise. As the organisation of investment markets improves, the risk of the predominance of speculation does, however, increase. In one of the greatest investment markets in the world, namely, New York, the influence of speculation is enormous... Speculators may do no harm as bubbles on a steady stream of enterprise. But the position is serious when enterprise becomes the bubble on a whirlpool of speculation. When the capital development of a country becomes a by-product of the activities of a casino, the job is likely to be ill-done. (Keynes, 1936, pp. 158-9)

Exatamente este tipo de problema é colocado pelo desenvolvimento financeiro recente, acelerado pelo processo de globalização. Ou seja, a liquidez ganha por esses novos ativos, que são transacionados em escala global, ao invés de roubar o

\footnotetext{
${ }^{14}$ Para maiores detalhes sobre a relação entre esses dois motivos e a incerteza, ver Dequech, 2000.

${ }^{15}$ Kregel (1996) mostra que até os investimentos diretos, hoje, são líquidos e sujeitos a uma grande volatilidade.

${ }^{16}$ Dow desenvolve bem essa discussão em Dow, 1993.
} 
papel da moeda enquanto referência de liquidez e invalidar a teoria da preferência pela liquidez, ampliou a especulação e, ao fazer isso, ampliou o papel da moeda enquanto limite ao crescimento das economias monetárias de produção, uma vez que intensificou a demanda por moeda decorrente do motivo especulação.

\section{CONCLUSÕES}

O artigo procurou responder a críticas externas à teoria pós-keynesianas que observam o desenvolvimento financeiro recente e o processo de globalização como elementos que, ao dotar ativos de um nível de liquidez elevado, inviabilizam a teoria da preferência pela liquidez de Keynes, que é um dos pilares para a observação do desemprego involuntário em economias monetárias de produção.

$\mathrm{O}$ artigo demonstrou que a moeda nacional e apenas ela continua sendo o limite máximo de liquidez e isso se dá mesmo em um contexto em que moedas internacionais são transacionadas livremente. Este fato decorre de ser a moeda a base para a realização dos contratos salariais e esse ser um dos elementos que the confere o prêmio máximo de liquidez. Portanto, por maior que seja a liquidez destes outros ativos, a moeda continua sendo a referência de liquidez. Nesse sentido, em economias monetárias de produção em que tempo histórico e incerteza são fundamentais, apenas a moeda responde de forma adequada à preferência pela liquidez e dadas suas duas especificidades fundamentais: baixas ou negligíveis elasticidades de produção e substituição, ela é que representa o limite à acumulação.

O processo de desenvolvimento financeiro e internacionalização da acumulação financeira gerou, sim, o resultado oposto ao pretendido pelos críticos acima mencionados. Ou seja, uma exacerbação do caráter especulativo, o que culminou com a ampliação da preferência pela liquidez decorrente do motivo especulação.

\section{REFERÊNCIAS}

ARESTIS, P. e PALIGINIS, E. (2000). "Globalization, Regionalism and National Economic Policies". In Toporowski, J., Political Economy and the new Capitalism. London: Routledge, 2000.

ARESTIS, P.; DEMETRIADES, P.; FATTOUH, B. e MOURATIDIS, K. (2002). “The Impact of Fianancial Liberalization Policies on Financial Development: Evidence from Developing Economies”. International Journal of Finance and Economics, vol. 7, 2002.

ARESTITS, P. e GLICKMAN, M. (2002). "Financial Crisis in Southeast Asia: Dispelling Illusion the Minskyan Way". Cambridge Journal of Economics, vol. 26, 2002. BRUNHOFF, S. (1982). Etat et Capital. Paris: FM/Foudations.

CARVAlHO, F.C. (1992). "Moeda, Produção e Acumulação: Uma Perspectiva Pós-Keynesiana”. In Silva, M.L.F, Moeda e Produção: Teorias Comparadas. Brasilia: Editora Universidade de Brasília, 1992. CARVALHO, FC. (1997). "Financial Innovation and Post Keynesian Approach to the 'Process of Capital Formation'”, Journal of Post Keynesian Economics, vol. 19, n 3, 1997.

CARVALHO, FJ.C. (2000). "The Changing Role and Strategies of the IMF and the Perspectives for the Emerging Countries”. Revista de Economia Politica, 20 (1), 2000. 
CHASNAIS, F. (1995). “A Globalização e o Curso do Capitalismo de Fim de Século”, Economia e Sociedade, vol. 5, dezembro de 1995.

CHICK, V. (1983). Macroeconomics After Keynes. Cambridge: MIT Press, 1983. DAVIDSON, P. (1978). Money And The Real World. London: Macmillan, 1978.

DEQUECH, D. (2000). “Asset Choice, Liquidity Preference, and Rationality under Uncertainty”. Journal of Economic Issues, vol. XXXIV, n ${ }^{\circ} 1,2000$.

DOW, S.C. (1993). Money and the Economic Process. Edward Elgar, Aldershot Hants, 1993.

DOW, S.C.(1995). "Liquidity Preference in International Finance: The Case of Developing Countries". In Wells, P. (ed), Post Keynesiana Economic Theory. London: Kluwer, 1995.

DOW, S.C. (1999). “International Liquidity Preference and Endogenous Credit Creation”. In Harvey, J.T. and Deprez (eds.), Foundations of International Economics: A Post Keynesian Analysis. London: Routledge, 1999.

GOODHART, C.A.E. (1989). Money, Information and Uncertainty. London: Macmillan. GUTTMAN, R. (1994). How Credit-Money Shapes the Economy. New York: M.E.Sharpe.

KEYNES, J.M. (1936). The General Theory of Employment, Interest and Money. The Collected Writtings of John Maynard Keynes, vol. VII, Cambridge: Macmillan.

KEYNES, J.M. (1937). "The General Theory of Employment". Quarterly Journal of Economics, no 51, February.

KEYNES, J.M. (1973a). The General Theory. Part I: Preparation. Collected Writings of John Maynard Keynes, vol. XIII, Cambridge: Macmillan.

KEYNES, J.M. (1973b). "Alternative Theories of the Rate of Interest". The General Theory and After. Part II: Defence and Development, Collected Writings of John Maynard Keynes, vol. XIV, Cambridge: Macmillan.

KEYNES, J.M. (1973c). “'Ex Ante' Theory of the Rate of Interest”. The General Theory and After. Part II: Defence and Development, Collected Writings of John Maynard Keynes, vol. XIV, Cambridge: Macmillan.

KEYNES, J.M. (1973d). "The Process of Capital Formation”. The General Theory and After. Part II: Defence and Development, Collected Writings of John Maynard Keynes, vol. XIV, Cambridge: Macmillan, Cambridge.

KEYNES, J.M. (1979). The General Theory and After: A Supplement. The Collected Writings of John Maynard Keynes, Vol. XXIX, 1979.

KREGEL, J.A. (1984). “Constraints on the Expansion of Output and Employment: Real or Monetary?”. Journal of Post Keynesian Economics, vol. VII, n 2, winter 1984-85.

KREGEL, J. (1996). "Riscos e Implicações da Globalização Financeira para a Autonomia de Políticas Nacionais". Economia e Sociedade, n 7, Dezembro de 1996.

MOLLO, M.L.R. e AMADO, A.M. (2000). "Globalização e Blocos Regionais: considerações teóricas e conclusões de política econômica”. Anais do V Encontro de Economia Política, 2000.

PLIHON, D. (1995). “A ascensão das finanças especulativas”, Economia e Sociedade, vol. 5, 1995. SHACKLE, G.L.S. (1983). The Years of High Theory. Cambridge: Cambridge University Press. SHACKLE, G.L.S. (1968). Expectations, Investment and Income. Oxford: Oxford University Press. 